\title{
The influence of chemical activation on hardness of dual-curing resin cements
}

\section{A influência da ativação química na dureza de cimentos resinosos duais}

\author{
Renata Garcia Fonseca* \\ Carlos Alberto dos Santos Cruz ${ }^{* *}$ \\ Gelson Luis Adabo**
}

\begin{abstract}
During the cementation of metallic restorations, the polymerization of dual-curing resin cements depends exclusively on chemical activation. This study evaluated the influence of chemical activation compared with dual-curing (chemical and light activation), on the hardness of four dual-curing resin cements. In a darkened environment, equal weight proportions of base and catalyst pastes of the cements Scotchbond Resin Cement, Variolink II, Enforce and Panavia F were mixed and inserted into moulds with cavities of 4 mm in diameter and $2 \mathrm{~mm}$ in height. Subsequently, the cements were: 1) not exposed to light (chemical activation = self-cured groups) or 2) photoactivated (dual-curing = dual-cured groups). The Vickers hardness number was measured at 1 hour, 24 hours and 7 days after the start time of cements' spatulation. For all the cements, the hardness values of selfcured groups were lower than those of the respective dual-cured groups at 1 hour and 24 hours. At 7 days, this behavior continued for Variolink II and Panavia F, whilst for Scotchbond Resin Cement and Enforce there was no statistical difference between the two activation modes. All cements showed a significant increase in their hardness values from 1 hour to 7 days for both activation modes. Of the self-cured groups, Scotchbond Resin Cement and Variolink II presented the highest and the lowest hardness values, respectively, for all three times tested. Within the limitations of this study, up to the time of $24 \mathrm{~h}$, chemical activation alone was unable to promote similar hardness as to that obtained with dual-curing.
\end{abstract}

DESCRIPTORS: Resin cements; Hardness; Dental materials.

\begin{abstract}
RESUMO: Na cimentação de restaurações metálicas, a polimerização dos cimentos resinosos duais depende exclusivamente da ativação química. Este estudo avaliou a influência da ativação química, comparada à dupla ativação (química e pela luz), na dureza de 4 cimentos resinosos duais. Em ambiente isento de luz, quantidades iguais em massa das pastas base e catalisadora dos cimentos Scotchbond Resin Cement, Variolink II, Enforce e Panavia F foram espatuladas e inseridas em matrizes com cavidade de $4 \mathrm{~mm}$ de diâmetro e $2 \mathrm{~mm}$ de altura. A seguir, os cimentos foram: 1) mantidos no escuro (ativação química = grupos quimicamente ativados) ou 2) fotopolimerizados (dupla ativação = grupos duais). A dureza Vickers foi obtida 1 hora, 24 horas e 7 dias após o início da espatulação dos cimentos. Em todos os cimentos, a dureza dos grupos quimicamente ativados foi menor que a dos respectivos grupos duais nos tempos de 1 hora e de 24 horas. Aos 7 dias, esse comportamento foi mantido pelo Variolink II e Panavia F, enquanto para o Scotchbond Resin Cement e para o Enforce não houve diferença estatisticamente significante entre os dois métodos de ativação. Todos os cimentos mostraram aumento significativo de dureza de 1 hora para 7 dias, em ambos os métodos de ativação. Dentre os grupos quimicamente ativados, o Scotchbond Resin Cement e o Variolink II mostraram, respectivamente, a maior e a menor dureza nos três tempos testados. Dentro dos limites deste estudo, até o período de 24 horas, a ativação exclusivamente química não foi capaz de promover dureza semelhante à obtida pela dupla ativação.
\end{abstract}

DESCRITORES: Cimentos de resina; Dureza; Materiais dentários.

\section{INTRODUCTION}

The clinical use of resin cements has increased greatly. These cements are mostly composed of monomers such as Bis-GMA, TEGDMA and UEDMA, reinforced with varying amounts of inorganic fillers. Regarding the activation mode, resin cements are available in photoactivated, chemically activated and dual-curing formulations and selection is based primarily on the intended use.

Dual-curing resin cements have been used not only for cementing indirect aesthetic ceramic and composite resins restorations but, more recently, also for cementing metallic restorations.

\footnotetext{
*PhD, Assistant Professor of Dental Materials; **PhDs, Associate Professors of Dental Materials - Department of Dental Materials and Prosthodontics, School of Dentistry of Araraquara, São Paulo State University.
} 
Fonseca RG, Cruz CAS, Adabo GL. The influence of chemical activation on hardness of dual-curing resin cements. Braz Oral Res 2004;18(3):228-32.

In aesthetic restorations, a portion of the light emitted from the photo-polymerization unit is absorbed by the restorative material and is not transmitted to the cement ${ }^{2,11,16}$. In these situations, cement areas that have received insufficient light intensity for activating the photo-sensitive substances depend upon chemical activation in order to assure polymerization. Reports in literature, however, have related that ceramics and composite resins of greater thickness ${ }^{6,7,17}$ and lower translucency ${ }^{17}$ result in reduced conversion of the dual-cured cements. In order to try to reduce this effect, longer exposure times are necessary, but not always enough.

For metallic restorations, the polymerization of cements is exclusively dependent on chemical activation, since the metal forms a physical barrier to transmission of light, making photoactivation impossible.

However, studies indicate that chemical activation alone is insufficient for dual-curing resin cements to achieve maximum conversion ${ }^{4-8,13,15}$. Just like the quantity and quality of polymeric and inorganic phases, efficacy of the setting mechanisms has a direct influence on the mechanical and biologic properties of resin cements ${ }^{1,7,14}$. According to $\mathrm{McComb}^{12}$ (1996), complete polymerization of resin cements is essential for strength, retention and longevity of restorations. In addition, inadequate cure can also be a causative factor in postoperative sensitivity and biocompatibility problems ${ }^{12}$. Therefore, these materials, available in dual-curing formulation, should be able to reach a high degree of conversion either in the presence or absence of light.

The purpose of the present study was to evaluate the influence of chemical activations compared with dual-curing activation on cement hardness, which is an indicator degree of conversion of four dual-curing resin cements.

\section{MATERIALS AND METHODS}

Four commercial dual-curing resin cements were tested (Table 1).

Equal weights $(0.10 \mathrm{~g})$ of base and catalyst pastes of each material were obtained using an analytical balance (Sartorius, Göttingen, Germany) and were spatulated according to manufacturers' directions.

After spatulation, cements were inserted into acrylic resin moulds with circular cavities of $4 \mathrm{~mm}$ in diameter and $2 \mathrm{~mm}$ in height. Moulds were filled
TABLE 1 - Dual-curing resin cements studied.

\begin{tabular}{l|l}
\hline \multicolumn{1}{c|}{ Brand name } & \multicolumn{1}{c}{ Manufacturer } \\
\hline $\begin{array}{l}\text { Scotchbond Resin } \\
\text { Cement }\end{array}$ & $\begin{array}{l}\text { 3M Co., St. Paul, } \\
\text { MN, USA }\end{array}$ \\
\hline Variolink II & $\begin{array}{l}\text { Vivadent, Schaan, } \\
\text { Liechtenstein }\end{array}$ \\
\hline Enforce & $\begin{array}{l}\text { Dentsply, Petrópolis, } \\
\text { RJ, Brazil }\end{array}$ \\
\hline Panavia F & $\begin{array}{l}\text { Kuraray Co., Umeda, } \\
\text { Osaka, Japan }\end{array}$ \\
\hline \hline
\end{tabular}

with a slight excess of material. A mylar strip (Probem, Catanduva, Brazil), a microscope slide, a metallic support with an opening to allow photoactivation and a $1 \mathrm{~kg}$ weight were positioned on top of the resin cements to permit the overflow of material in excess. All these procedures, with the exception of weighing, were performed inside an $\mathrm{X}$-ray film development box (Odontologic Indústria e Comércio Ltda., São Paulo, Brazil) shielding the materials from exposure to ambient light.

Subsequently, the cements were submitted to one of the following activation modes: 1) cements of the self-cured groups (chemical activation alone) remained in these conditions (described above) for 60 seconds; and 2) the upper surfaces of the cements of the dual-cured groups (dual-curing) were photoactivated for 60 seconds, using a halogen light source (Curing Light 2500 photo-polymerization unit, 3M Co., St. Paul, MN, USA) with $510 \mathrm{~mW} / \mathrm{cm}^{2}$ intensity, and were used as control groups.

Afterwards, the specimens were stored dry, in lightproof containers at $37^{\circ} \mathrm{C}$, until testing. The Vickers hardness numbers (VHN) were measured at 1 hour, 24 hours and 7 days after the start time of cements' spatulation, using a M-Testor microhardness tester (Otto Wolpert-Werke, Ludwigshafen, Germany), a Vickers diamond (Buehler, Lake Bluff, USA) and a force of $0.3 \mathrm{~N}$, applied for 30 seconds.

Twenty-four experimental conditions were tested: 4 cements, 3 times and 2 activation modes. For each condition, 5 specimens were tested. For each test specimen, 12 hardness measurements were performed, three for each quadrant of the specimen. A mean was calculated for each test specimen using these measurements and, afterwards, for each experimental condition. 
Fonseca RG, Cruz CAS, Adabo GL. The influence of chemical activation on hardness of dual-curing resin cements. Braz Oral Res 2004;18(3):228-32.

Statistical analysis was performed with the software GMC 8.1 statistical package (School of Dentistry of Ribeirão Preto, University of São Paulo, Brazil).

Three comparative analyses were performed:

1. between the activation modes for each cement and time studied, using the Student's $t$-test;

2. between the 1-hour and 7-days conditions for each cement and activation mode, also using the Student's $t$-test;

3. between the self-cured groups of all cements for each of the three times, using ANOVA and Tukey's test. All statistical tests used a 95\% confidence level.

\section{RESULTS}

Means and standard deviations of the Vickers hardness numbers (VHN) obtained from self-cured and dual-cured groups of the examined cements at the three test intervals are presented in Table 2.

At 1 hour and 24 hours, for all cements, dual-curing activation produced higher Vickers hardness than chemical activation $(p<0.05)$. At 7 days, this still held true for the Variolink II and Panavia F cements ( $<0.05)$, whilst there was no difference between the two activation modes for the Scotchbond Resin Cement and Enforce cements ( $p>0.05)$.

In terms of percentage, at 1 hour, the selfcured groups of Scotchbond Resin Cement, Variolink II, Enforce and Panavia F cements demonstrated $63 \%, 48 \%, 77 \%$ and $55 \%$ of the hardness values of the respective dual-cured groups. By 7 days, these percentage values had increased to $96 \%, 94 \%, 97 \%$ and $83 \%$, respectively.

All resin cements showed a significant increase in hardness values from 1 hour to 7 days for both activation modes $(\mathrm{p}<0.05)$. This increase was 2 to 4 times greater for the self-cured groups than for the dual-cured groups. Scotchbond Resin Cement, Variolink II, Enforce and Panavia F cements presented percentage increases of $18 \%$, $15 \%, 18 \%$ and $23 \%$ for the dual-cured groups and of $46 \%, 57 \%, 35 \%$ and $49 \%$ for the self-cured groups.

The comparison of the self-cured groups for all cements at each of the three times analyzed reveals that Scotchbond Resin Cement showed the highest hardness value achieved by the cements at 1 hour $(\mathrm{p}<0.05)$. Enforce and Panavia $\mathrm{F}$ had statistically similar hardness values, while Variolink II presented the lowest hardness value of all cements. At 24 hours ( $p<0.05)$, Panavia F, together with Scotchbond Resin Cement showed the highest hardness values, followed by Enforce and Variolink II cements, which were statistically different. At 7 days ( $<0.05)$, there were statistical differences between all the cements, with Scotchbond Resin Cement showing the best results, followed by Panavia F, Enforce and Variolink II.

\section{DISCUSSION}

Ideally, dual-curing resin cements, when activated by chemical means alone, should demonstrate hardness, which is an indicator of degree of conversion, very similar to that achieved when submitted to dual-curing activation even in the initial period after cementation.

The present study, however, demonstrated that until 24 hours, for all the cements evaluated, the hardness values for the self-cured groups were significantly lower than the respective values for the dual-cured groups. A similar trend has been observed among other commercial brands of dual-curing resin cements in previous publications $^{3,6-9}$

TABLE 2 - Means and standard deviations of Vickers hardness number.

\begin{tabular}{l|c|c|c|c|c|c}
\hline \hline \multirow{2}{*}{\multicolumn{1}{c}{ Cements }} & \multicolumn{2}{|c|}{1 hour } & \multicolumn{2}{c|}{24 hours } & \multicolumn{2}{c}{7 days } \\
\cline { 2 - 7 } & DCG & SCG & DCG & SCG & DCG & SCG \\
\hline Scotchbond Resin Cement & $59.7(3.3)$ & $37.6(3.1)$ & $71.8(4.0)$ & $60.1(4.9)$ & $73.2(4.7)$ & $70.4(3.6)$ \\
\hline Variolink II & $35.8(0.5)$ & $17.1(0.5)$ & $43.2(1.1)$ & $31.1(0.9)$ & $42.0(0.4)$ & $39.4(0.4)$ \\
\hline Enforce & $42.8(1.6)$ & $32.9(1.4)$ & $52.1(1.0)$ & $42.2(0.8)$ & $52.5(1.7)$ & $51.0(2.4)$ \\
\hline Panavia F & $55.0(1.8)$ & $30.1(1.3)$ & $62.7(2.8)$ & $55.7(2.2)$ & $71.7(2.7)$ & $59.7(1.2)$ \\
\hline \hline
\end{tabular}

Results in parentheses indicate standard deviations. DCG means dual-cured group and SCG means self-cured group. 
Fonseca RG, Cruz CAS, Adabo GL. The influence of chemical activation on hardness of dual-curing resin cements. Braz Oral Res 2004;18(3):228-32.

In other studies that utilized infrared spectrometry to evaluate the degree of conversion of the dual-curing resin cements as activation mode, significantly superior results were also observed when specimens were exposed to photoactivation ${ }^{4,13,15}$.

Variability between the cements regarding the degree of hardness achieved via chemical activation alone was observed, however, in relation to the respective dual-cured groups. At 1 hour, the hardness value of the Variolink II self-cured group reached $48 \%$ of the hardness value obtained in the dual-cured group, whilst for the Enforce cement, the hardness value of the self-cured group reached $77 \%$ of the hardness value of the dual-cured group. The other cements fell in between these two extremes. At 7 days, the average hardness value for the self-cured groups for Scotchbond Resin Cement, Enforce and Variolink II cements were quite close to the values for the respective dual-cured groups. In contrast, for Panavia F, there were great differences between the results obtained through the self-cured and the dual-cured treatments, demonstrating that this cement depends more on photoactivation than the other cements.

The significant increase in hardness value related to time, for both activation modes, as was observed in this study, has also been demonstrated in previous studies ${ }^{7,8}$. In a general manner, the highest percentage increases observed in the selfcured groups could conceivably be related to the lower hardness values seen at 1 hour, compared to the values of the respective dual-cured groups. This finding may be explained by the difference in velocity between the two activation mechanisms. Photoactivation results in an initial, fast hardening of the resin cement, yielding a hardness value at 1 hour significantly higher than that of the self-cured groups. Chemical activation results in a slow, progressive hardening. Lee, $\mathrm{Um}^{10}$ (2001), using thermal analysis, observed that the cure speed of dual-curing resin cements by light exposure was 5-20 times greater than by chemical cure.

The comparative study between the groups of self-cured resin cements at each of the three analyzed times showed that, even when considering a single activation mode, the cements exhibited different degrees of hardness.

At all analyzed times, Scotchbond Resin Cement and Variolink II showed, respectively, the highest and lowest hardness values, with the other cements being in an intermediate position. At 1 hour, the mean hardness value for Scotchbond Resin Cement was twice as great as the mean value for Variolink II, whereas Enforce and Panavia F cements presented statistically similar hardness values. At 7 days, Scotchbond Resin Cement and Enforce cements, which show no statistical difference between the two activation modes, had their hardness values stabilized at the level of $70 \mathrm{VHN}$ and 50 VHN, respectively. Although Variolink II, even at 7 days, showed significant difference between the two activation modes, the two mean hardness values were close to the level of $40 \mathrm{VHN}$. Finally, the Panavia F cement, even showing a considerable difference between the two activation modes, had a hardness value for the self-cured group that was significantly higher than that of the Enforce and Variolink II cements.

The reason for this behavior variation of the cements studied is more related to the way these cements are formulated. Cement behavior is the consequence of not only the efficacy and amount of chemical and photochemical activators used, but also the general composition of the cement; for example, types and proportions of monomers used in each of them ${ }^{13}$.

Additional studies that evaluate important properties such as flexural strength, fracture toughness and modulus of elasticity, amongst others, should be performed to obtain the most reliable parameters for the use of these materials.

\section{CONCLUSIONS}

Within the limits of this in vitro study, the authors concluded:

- Up to the time of $24 \mathrm{~h}$, chemical activation alone was unable to promote similar hardness to that obtained by dual-curing (chemical and light activation).

- As with dual-curing activation, chemical activation alone also promoted progressive hardness from 1 hour to 7 days.

- Scotchbond Resin Cement and Variolink II showed, respectively, the highest and the lowest hardness values for the three times tested.

\section{ACKNOWLEDGMENTS}

The authors would like to thank FAPESP (The State of São Paulo Research Foundation 98/14880-0) for financial support. 
Fonseca RG, Cruz CAS, Adabo GL. The influence of chemical activation on hardness of dual-curing resin cements. Braz Oral Res 2004;18(3):228-32.

\section{REFERENCES}

1. Attar N, Tam LE, McComb D. Mechanical and physical properties of contemporary dental luting agents. J Prosthet Dent 2003;89(2):127-34.

2. Blackman R, Barghi N, Duke E. Influence of ceramic thickness on the polymerization of light-cured resin cement. J Prosthet Dent 1990;63(3):295-300.

3. Braga RR, Cesar PF, Gonzaga CC. Mechanical properties of resin cements with different activation modes. J Oral Rehabil 2002;29(3):257-62.

4. Caughman WF, Chan DCN, Rueggeberg FA. Curing potential of dual-polymerizable resin cements in simulated clinical situations. J Prosthet Dent 2001;85(5):479-84.

5. Darr AH, Jacobsen PH. Conversion of dual cure luting cements. J Oral Rehabil 1995;22(1):43-7.

6. El-Badrawy WA, El-Mowafy OM. Chemical versus dual curing of resin inlay cements. J Prosthet Dent 1995;73(6):51524.

7. El-Mowafy OM, Rubo MH, El-Badrawy WA. Hardening of new resin cements cured through a ceramic inlay. Oper Dent 1999;24(1):38-44.

8. Hasegawa EA, Boyer DB, Chan DCN. Hardening of dualcured cements under composite resin inlays. J Prosthet Dent 1991;66(2):187-92.

9. Hofmann N, Papsthart G, Hugo B, Klaiber B. Comparison of photo-activation versus chemical or dual-curing of resinbased luting cements regarding flexural strength, modulus and surface hardness. J Oral Rehabil 2001;28(11):1022-8.
10. Lee IB, Um CM. Thermal analysis on the cure speed of dual cured resin cements under porcelain inlays. J Oral Rehabil 2001;28(2):186-97.

11. Linden JJ, Swift EJ Jr, Boyer DB, Davis BK. Photoactivation of resin cements through porcelain veneers. J Dent Res 1991;70(2):154-7.

12. McComb D. Adhesive luting cements - classes, criteria and usage. Compend Contin Educ Dent 1996;17(8):75973.

13. Peutzfeldt A. Dual-cure resin cements: in vitro wear and effect of quantity of remaining double bonds, filler volume, and light curing. Acta Odontol Scand 1995;53(1):2934.

14. Rosenstiel SF, Land MF, Crispin BJ. Dental luting agents: a review of the current literature. J Prosthet Dent 1998;80(3):280-301.

15. Rueggeberg FA, Caughman WF. The influence of light exposure on polymerization of dual-cure resin cements. Oper Dent 1993;18(2):48-55.

16. Strang R, McCrosson J, Muirhead GM, Richardson SA. The setting of visible-light-cured resins beneath etched porcelain veneers. Br Dent J 1987;163(5):149-51.

17. Uctasli S, Hasanreisoglu U, Wilson HJ. The attenuation of radiation by porcelain and its effect on polymerization of resin cements. J Oral Rehabil 1994;21(5):565-75.

Received for publication on Sep 13, 2003 Accepted for publication on May 19, 2004 